\title{
A systematic review and meta-analysis of the seroprevalence of Toxoplasma gondii in cats in mainland China
}

Huan Ding ${ }^{1,2}$, Yu-Meng Gao ${ }^{1,2}$, Yao Deng ${ }^{1,2}$, Poppy H. L. Lamberton ${ }^{3,4}$ and Da-Bing Lu, L $^{1 *}$

\begin{abstract}
Background: Toxoplasmosis is caused by Toxoplasma gondii which can infect all warm-blooded animals. As the most common feline definitive host, cats play a vital role in the transmission of T. gondii. However, national estimates of the seroprevalence of T. gondii in cats in mainland China are lacking, and therefore a systematic review and meta-analysis were performed to provide insight into national environmental transmission levels and potential transmission to humans.

Methods: Studies published up until July 1, 2016, on T. gondii seroprevalence in cats within mainland China were searched for in CNKI, WanFang, CBM, PubMed, Embase and through the reference lists of resulting articles. The seroprevalence with its $95 \%$ confidence interval (Cl) for each individual study was presented, and then point estimates and their $95 \%$ confidence intervals $(\mathrm{Cls})$ of pooled seroprevalence were calculated. Subgroup analyses were performed according to potential risk factors.

Results: A total of 38 eligible studies, published between 1995 to 2016, covering fifteen provinces and municipalities, and involving 7,285 cats, were included. The seroprevalence in cats per study ranged from 3.9 to $79.4 \%$ with a median of $20.3 \%$. As substantial heterogeneity existed among studies, a random-effects model was used to estimate the pooled seroprevalence. The value of the point estimate seroprevalence was $24.5 \%$ (95\% Cl: $20.1-29.0)$. Seroprevalence in stray cats was significantly higher than in pet cats $(\mathrm{OR}=3.00,95 \% \mathrm{Cl}: 1.60-5.64)$. The seroprevalence increased significantly with cat age $(P=0.018)$ with $17.4 \%(95 \% \mathrm{Cl}: 7.6-27.2)$ in the group of $\leq 1$ year old, $19.5 \%(95 \% \mathrm{Cl}: 12.7-26.3)$ in the group of $\leq 3$ year-old and $31.6 \%$ (95\% Cl: $22.9-40.3)$ in the group of $>3$ year-old.

Conclusions: The seroprevalence of T. gondii in cats in mainland China was moderate and was associated with cat ownership and age. Due to the increasing prevalence of pet cats in China and the intimate relationship between these cats and humans, this might present a significant exposure risk, particularly for China's large susceptible population. Therefore, further research is needed into the links between cat ownership and human T. gondii infection and how to reduce T. gondii exposure in humans via cat contacts and the environmental contamination with $T$. gondii oocysts by cats.
\end{abstract}

Keywords: Toxoplasma gondii, Cats, Mainland china, Seroprevalence, Meta-analysis

\footnotetext{
* Correspondence: Ludabing@suda.edu.cn

'Department of Epidemiology and Statistics, School of Public Health, Soochow University, Suzhou 215123, China

${ }^{2}$ Jiangsu Key Laboratory of Preventive and Translational Medicine for Geriatric Diseases, School of Public Health, Soochow University, Suzhou 215123, People's Republic of China

Full list of author information is available at the end of the article
} 


\section{Background}

Toxoplasmosis is caused by the obligate, intracellular protozoan Toxoplasma gondii, a widespread zoonotic parasite which can infect all warm-blooded animals [1], and is one of the most common zoonosis in the world [2]. Its wide distribution may be attributed to complex transmission patterns and parasite coevolution with multiple hosts [3]. Felids are the only definitive host and one infected cat can discharge millions of infective oocysts in faeces, although only over a few days after primary infection $[4,5]$. Intermediate hosts (such as humans, rodents and other animals) can be infected through ingestion of oocysts from the environment (food contaminated with oocysts or direct contact with oocysts excreted in cats faeces), consumption of undercooked meat containing $T$. gondii tissue cysts $[6,7]$, or congenitally when parasites in a pregnant women infected with $T$. gondii for the first time spread to the foetus through the placenta often causing abortion, premature birth, stillbirth, malformation and/or neonatal congenital infection [8].

Although T. gondii infections of immunocompetent people are typically considered asymptomatic, infections in immunocompromised individuals, such as those with AIDS or organ transplant recipients, can result in severe consequences. For example, approximately $10 \%$ of AIDS patients in the USA and up to $30 \%$ in Europe are estimated to die from toxoplasmosis [9]. Moreover, positive correlations between previously assumed asymptomatic T. gondii infections with the incidences of schizophrenia [10], car accident [11], epilepsy [12] and suicide [13] in humans have now been reported. The seroprevalence of toxoplasmosis in psychiatric patients was once reported to be as high as 50\% [11]. Globally, in 2010 T. gondii was estimated to have caused 10.28 million foodborne illnesses and 0.83 million Disability Adjusted Life Years (DALYs) [14]. These all highlight the global public health importance of this infection in human populations.

Toxoplasmosis remains a public health problem in mainland China, as there is an increasing number of AIDS patients with an estimate of 650,000 in 2005 increasing to 780, 000 in 2011 [15] and a huge number of women of childbearing age, estimated to be approximately 375.8 million in 2013 [16]. Cats play a major role in the transmission of $T$. gondii, pet cats may therefore be an important potential source of human toxoplasmosis due to their intimate association with humans, particularly if they are free-roaming and may themselves be exposed to environmental T. gondii parasites. The seroprevalence of $T$. gondii in pet cat owners (11.86\%) is higher than in non-pet cat owners (7.38\%) [17] or than in the general population (7.88\%) surveyed in 2001-2004 [18], and the seroprevalence in some areas of China was as high as $34 \%$ [19]. With the rapid development of the
Chinese economy and continuous improvement of living standards in China the number of families which have pet cats is increasing. For example, it was estimated that approximately 100 million cats were considered pets in 2010 in China [20], with a growth rate of $10 \%$ over the subsequent years [21].

To the authors' knowledge, there is no study which has addressed the overall seroprevalence of $T$. gondii infection in cats across mainland China nor the risk factors associated with these infections. Therefore, this systematic review and meta-analysis was performed to determine the seroprevalence of $T$. gondii in cats in mainland China over the last 20 years and to assess the potential risk factors related to $T$. gondii seroprevence in cats. The purpose was to provide an increased understanding to aid parasite control, as evidence grows of its importance for human health [22, 23], particularly in China with such a large susceptible population.

\section{Methods}

The study was conducted according to the PRISMA guideline (Preferred Reporting Items for Systematic Reviews and Meta-Analyses) [24]. The PRISMA checklist was used to ensure inclusion of relevant information in the analysis (see Additional file 1).

\section{Search strategy}

A literature search was conducted for publications from January 1, 1995 to July 1, 2016. We aimed to include all published studies in English or Chinese on seroprevalence of $T$. gondii in cats across mainland China. We identified published studies within the following five bibliographic databases (three in Chinese and two in English): "toxoplasma gondii" and "cat" in Chinese ("gongxingchong/or gongxingti", and "mao", respectively) were used as search terms in the Chinese databases (China National Knowledge Infrastructure (CNKI), WanFang and The Chinese Biomedical Literature Database (CBM)), and "toxoplasma" and "china" and "cats" were MeSH terms in the PubMed online and "toxoplasma" and "china" and "cats" were emtree term-exploded in Embase. We also visually scanned all reference lists from relevant studies in an attempt to locate additional studies that may not have been identified by searching the electronic databases. We did not contact authors of original studies for additional information. No attempt was made to retrieve unpublished studies. Full text articles were downloaded or obtained through library resources.

\section{Inclusion and exclusion criteria}

A total of 53 full texts were read for eligibility screening (Fig. 1). Selected manuscripts needed to fulfil the following inclusion criteria: (i) cross-sectional study; (ii) locations within mainland China; (iii) targeted objectives included 


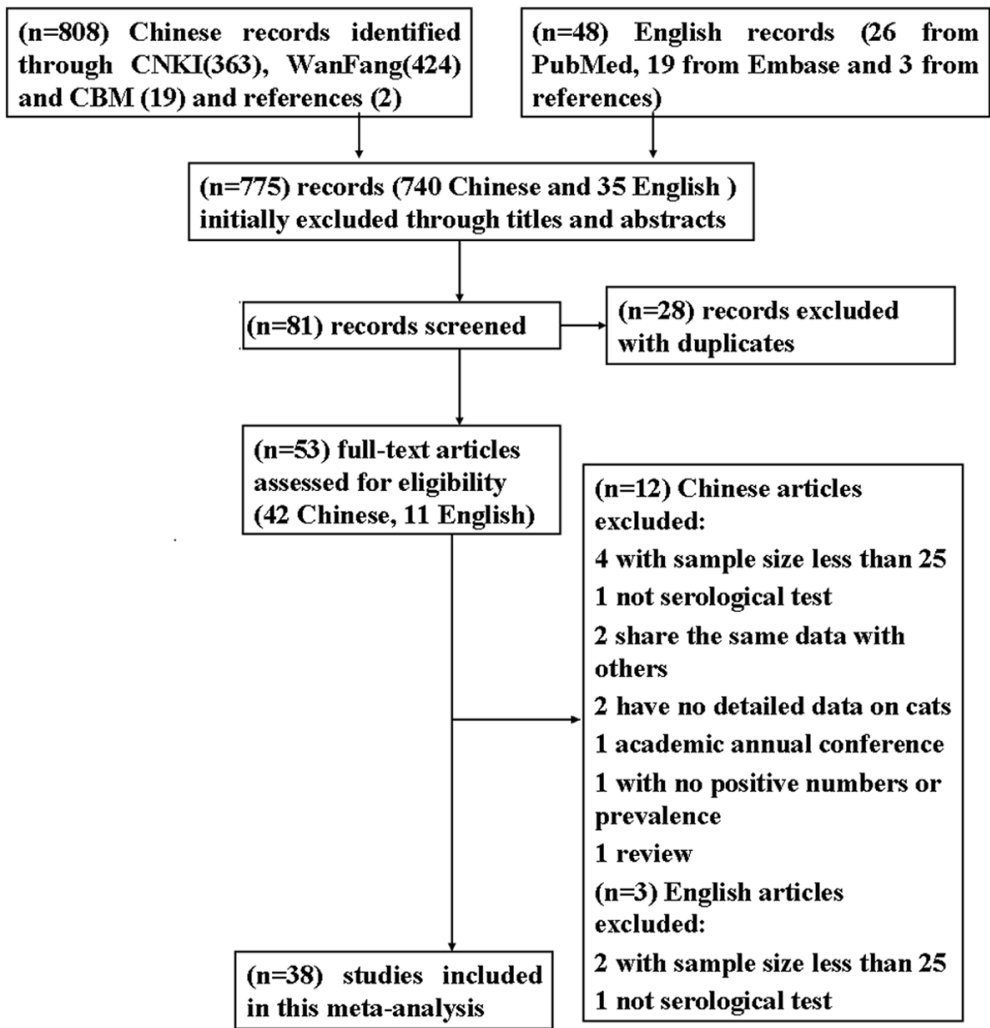

Fig. 1 Flow diagram of the selection of eligible studies

cats; (iv) serological diagnostic methods were used; (v) exact total and positive numbers were provided; and (vi) a sample size greater than 25 (for statistic calculations [25]). Studies were excluded if they did not fulfil all of these criteria.

\section{Quality of the studies}

We evaluated risk of bias among the included studies using a quality assessment checklist. The following items were examined and given a score based on a simple scale system (2 for "yes", 0 for "no", or 1 for "unsure").

- Was the research question/objective clearly described and stated?

- Was the sampling method described in detail?

- Was the period of study clearly stated?

- Was the serological test method clearly pointed out?

- Were the subjects categorized into different subgroups?

\section{Data extraction}

For data extraction, the detailed characteristics of each study were extracted using a pre-designed data-collection excel form. Information was recorded as follows: study characteristics (the first author, year of publication, year of study, location); study methodology (survey method in detail, sampling method and the serological test used); characteristics of cats (pet or stray, gender, age category, survey season and region); sample size; the number of the positives and/or seroprevalence of $T$. gondii; score of each study.

\section{Data analysis}

While the inverse variance method is widely used and works for prevalence proportions around 0.5 , two problems arise when the proportions get closer to the limits of the 0 and 1 range. The first of these problems is that the confidence interval (CI) does not preclude confidence limits outside the $0-1$ range; the second problem is that a study gets a large weighting when the proportion becomes too small or too big [26]. Therefore, we here calculated seroprevalence estimates with the variance stabilising double arcsine transformation by the following formula: $\mathrm{t}$ $=\arcsin (\operatorname{sqrt}(r /(n+1)))+\arcsin (\operatorname{sqrt}((r+1) /(n+1)))$, where $\mathrm{t}=$ transformed seroprevalence, $\mathrm{r}=$ positive numbers and $n=$ sample size; se(t) $=\operatorname{sqrt}(1 /(n+0.5))$, where se $=$ standard error and the back transformation to a proportion is done using: $p=(\sin (\mathrm{t} / 2))^{2}[26]$.

\section{Pooling and heterogeneity analyses}

The seroprevalence and its 95\% CI for each study were first calculated, and then point estimates and their $95 \%$ 
Table 1 Characteristics of the eligible studies

\begin{tabular}{|c|c|c|c|c|c|c|c|c|c|}
\hline Author & Year & Region & $\begin{array}{l}\text { Period of } \\
\text { study }\end{array}$ & $\begin{array}{l}\text { Serological } \\
\text { method }\end{array}$ & Positivity & $\begin{array}{l}\text { Detailed information } \\
\text { on cats }\end{array}$ & $\begin{array}{l}\text { Total no. } \\
\text { of cats }\end{array}$ & $\begin{array}{l}\text { No. of positive } \\
\text { cats (\%) }\end{array}$ & $\begin{array}{l}\text { Quality } \\
\text { score }\end{array}$ \\
\hline $\begin{array}{l}\text { Fu et al. } \\
{[36]}\end{array}$ & 1995 & Shandong & 1991-1993 & $1 H A^{a}$ & $\geq 1: 64$ & No & 200 & $92(46.00)$ & 8 \\
\hline $\begin{array}{l}\text { Lu et al. } \\
\text { [41] }\end{array}$ & 1997 & Shanghai & 1994-1995 & $H A^{b}$ & $\geq 1: 80$ & $\begin{array}{l}\text { Gender, age, } \\
\text { Season }\end{array}$ & 142 & $54(38.01)$ & 10 \\
\hline $\begin{array}{l}\text { Chen et al. } \\
\text { [32] }\end{array}$ & 2001 & Hubei & & ELISA ${ }^{f}$ & $\begin{array}{l}\text { IgG or CAg } \\
\text { positive }\end{array}$ & No & 105 & $33(31.43)$ & 8 \\
\hline $\begin{array}{l}\text { Zhao et al. } \\
\text { [58] }\end{array}$ & 2001 & Shandong & & $\| H A^{a}$ & $\geq 1: 64$ & No & 185 & $82(44.32)$ & 7 \\
\hline $\begin{array}{l}\text { Chen et al. } \\
\text { [66] }\end{array}$ & 2003 & Shenzhen, Guangdong & & $\| H A^{a}$ & $\geq 1: 64$ & No & 65 & $12(18.46)$ & 6 \\
\hline $\begin{array}{l}\text { Yuan et al. } \\
\text { [54] }\end{array}$ & 2004 & Baoding, Hebei & $2000-2001$ & ELISA $^{9}$ & $\begin{array}{l}\operatorname{lgG} \text { or } \mathrm{CAg} \\
\text { positive }\end{array}$ & No & 75 & $43(57.33)$ & 9 \\
\hline $\begin{array}{l}\text { Yu et al. } \\
\text { [53] }\end{array}$ & 2006 & Beijing & & ELISA $^{c}$ & IgG positive & Gender, age & 128 & $18(14.06)$ & 9 \\
\hline $\begin{array}{l}\text { Dubey et al. } \\
\text { [35] }\end{array}$ & 2007 & Guangzhou, Guangdong & 2006 & MAT & $\geq 1: 40$ & No & 34 & $27(79.41)$ & 6 \\
\hline $\begin{array}{l}\text { Yu et al. } \\
\text { [51] }\end{array}$ & 2008 & Beijing & 1999-2005 & ELISA $^{c}$ & IgG positive & Gender, age & 335 & $50(14.93)$ & 9 \\
\hline $\begin{array}{l}\text { Huang et al. } \\
\text { [38] }\end{array}$ & 2008 & Haikou, Hainan & $2007-2008$ & ELISA $^{d}$ & IgG positive & No & 251 & $14(5.58)$ & 8 \\
\hline $\begin{array}{l}\text { Zhang et al. } \\
{[56]}\end{array}$ & 2009 & Guangzhou, Guangdong & & ELISA $^{d}$ & IgG positive & $\begin{array}{l}\text { Stray or pet, } \\
\text { gender, age }\end{array}$ & 206 & $52(25.24)$ & 9 \\
\hline $\begin{array}{l}\text { Sun et al. } \\
{[46]}\end{array}$ & 2009 & Beijing and neighbor & 2008 & ELISA $^{c}$ & IgG positive & Gender & 172 & $32(18.60)$ & 8 \\
\hline $\begin{array}{l}\text { Zhang et al. } \\
\text { [64] }\end{array}$ & 2009 & Beijiang, Xinjiang & & $H A^{a}$ & $\geq 1: 64$ & No & 42 & $3(7.14)$ & 8 \\
\hline $\begin{array}{l}\text { Lu et al. } \\
{[40]}\end{array}$ & 2010 & Huhehaote, Inner Monglia & 2009-2010 & ELISA $^{e}$ & IgG positive & Gender & 87 & $9(10.34)$ & 9 \\
\hline $\begin{array}{l}\text { Lu et al. } \\
\text { [65] }\end{array}$ & 2010 & Lanzhou, Gansu & $2008-2009$ & Test Paper ${ }^{k}$ & $\begin{array}{l}\text { antigen } \\
\text { positive }\end{array}$ & Age & 159 & $14(8.81)$ & 8 \\
\hline $\begin{array}{l}\text { Xie et al. } \\
{[50]}\end{array}$ & 2010 & Shenzhen, Guangdong & 2009-2010 & ELISA $^{d}$ & IgG positive & No & 278 & $13(4.68)$ & 9 \\
\hline $\begin{array}{l}\text { Zhang et al. } \\
\text { [55] }\end{array}$ & 2010 & Zhengzhou, Henan & 2009 & $\| H A^{a}$ & $\geq 1: 64$ & Gender, age & 58 & $9(15.52)$ & 10 \\
\hline $\begin{array}{l}\text { Chen et al. } \\
\text { [62] }\end{array}$ & 2010 & Shanghai & $2009-2009$ & $\| H A^{a}$ & $\geq 1: 64$ & Stray or pet & 270 & $65(24.07)$ & 9 \\
\hline $\begin{array}{l}\text { Qian et al. } \\
\text { [45] }\end{array}$ & 2010 & Beijing & & ELISA $^{h}$ & IgG positive & Stray or pet & 323 & $58(17.96)$ & 8 \\
\hline $\begin{array}{l}\text { Huang et al. } \\
{[37]}\end{array}$ & 2011 & Zhejiang & & Test Paper ${ }^{k}$ & $\begin{array}{l}\text { antigen } \\
\text { positive }\end{array}$ & Stray or pet & 341 & $91(26.69)$ & 10 \\
\hline $\begin{array}{l}\text { Wu et al. } \\
\text { [49] }\end{array}$ & 2011 & Lanzhou, Gansu & 2010-2011 & MAT & $\geq 1: 25$ & $\begin{array}{l}\text { Stray or pet, } \\
\text { Gender, age }\end{array}$ & 221 & $47(21.27)$ & 10 \\
\hline $\begin{array}{l}\text { Wang et al. } \\
{[48]}\end{array}$ & 2012 & Shanghai & 2010-2011 & ELISA $^{d}$ & IgG positive & Gender, age & 145 & $25(17.24)$ & 10 \\
\hline $\begin{array}{l}\text { Qian et al. } \\
\text { [44] }\end{array}$ & 2012 & Beijing & 2009-2011 & MAT & $\geq 1: 20$ & No & 64 & $37(57.81)$ & 8 \\
\hline $\begin{array}{l}\text { Qi et al. } \\
\text { [43] }\end{array}$ & 2012 & Beijing & 2011 & $\| H A^{a}$ & $\geq 1: 64$ & No & 176 & $7(3.98)$ & 9 \\
\hline $\begin{array}{l}\text { Wang et al. } \\
{[47]}\end{array}$ & 2012 & Zhengzhou, Henan & 2010-2011 & $\| H A^{a}$ & $\geq 1: 64$ & Age & 195 & $102(52.31)$ & 10 \\
\hline $\begin{array}{l}\text { Cui et al. } \\
{[63]}\end{array}$ & 2012 & Beijing & 2010-2011 & ELISA $^{c}$ & IgG positive & $\begin{array}{l}\text { Age, gender, } \\
\text { season }\end{array}$ & 561 & $119(21.21)$ & 8 \\
\hline
\end{tabular}


Table 1 Characteristics of the eligible studies (Continued)

\begin{tabular}{|c|c|c|c|c|c|c|c|c|c|}
\hline $\begin{array}{l}\text { Yu et al. } \\
\text { [52] }\end{array}$ & 2013 & Pudong, Shanghai & & ELISA $^{c}$ & IgG positive & Stray or pet & 27 & $5(18.52)$ & 8 \\
\hline $\begin{array}{l}\text { Zhuo et al. } \\
\text { [60] }\end{array}$ & 2013 & Taizhou, Jiangsu & 2012 & $\| H A^{a}$ & $\geq 1: 64$ & No & 215 & $43(20.00)$ & 9 \\
\hline $\begin{array}{l}\text { Wang et al. } \\
\text { [69] }\end{array}$ & 2013 & Fujian & 2012 & ELISA $^{d}$ & IgG positive & No & 530 & $238(45.00)$ & 7 \\
\hline $\begin{array}{l}\text { Liu et al. } \\
\text { [39] }\end{array}$ & 2014 & Zhenjiang, Jiangsu & 2013 & ELISA $^{\mathrm{d}}$ & $\lg G$ positive & Stray or pet & 116 & $24(20.69)$ & 10 \\
\hline $\begin{array}{l}\text { Deng et al. } \\
\text { [34] }\end{array}$ & 2014 & Changsha, Hunan & $2011-2012$ & ELISA ${ }^{c}$ & $\lg G$ positive & Gender, age & 75 & $21(28.00)$ & 10 \\
\hline $\begin{array}{l}\text { Fu et al. } \\
{[67]}\end{array}$ & 2014 & Xuzhou, Jiangsu & 2010-2012 & ELISA ${ }^{c}$ & $\lg G$ positive & No & 41 & $17(41.46)$ & 8 \\
\hline $\begin{array}{l}\text { Zhao et al. } \\
\text { [57] }\end{array}$ & 2015 & Beijing & 2012-2014 & ELISA ${ }^{c}$ & IgG positive & Season & 286 & $60(20.98)$ & 9 \\
\hline $\begin{array}{l}\text { Deng et al. } \\
\text { [33] }\end{array}$ & 2015 & Shanghai & 2014 & ELISA ${ }^{i}$ & IgG positive & No & 91 & $5(5.49)$ & 8 \\
\hline $\begin{array}{l}\text { Lai et al. } \\
\text { [68] }\end{array}$ & 2015 & Beijing & 2013 & ELISA ${ }^{i}$ & IgG positive & No & 48 & $2(4.17)$ & 8 \\
\hline $\begin{array}{l}\text { Mayilai et al. } \\
\text { [42] }\end{array}$ & 2015 & Kuche, Xinjiang & 2014 & ELISA & lgG positive & Gender, age & 87 & $34(39.08)$ & 8 \\
\hline $\begin{array}{l}\text { Zheng et al. } \\
\text { [59] }\end{array}$ & 2015 & Shandong & $2012-2013$ & ELISA ${ }^{e}$ & IgG positive & Gender, age & 589 & $23(3.90)$ & 10 \\
\hline $\begin{array}{l}\text { Cong et al. } \\
{[61]}\end{array}$ & 2016 & Lanzhou, Gansu & 2014-2015 & MAT & $\geq 1: 25$ & $\begin{array}{l}\text { Stray or pet, } \\
\text { Gender, age }\end{array}$ & 362 & $70(19.34)$ & 10 \\
\hline
\end{tabular}

Abbreviations: ELISA Enzyme Linked Immunosorbent Assay, IHA Indirect Haemagglutination test, MAT Modified Agglutination Test, Test Paper, test paper for TOXO-Ag

${ }^{a}$ The test kits were produced by Lanzhou Veterinary Research Institute, Chinese Academy of Agricultural Science (Cut-off titer 1:64)

${ }^{b}$ By Shanghai No. 2 Medical School, Parasite Research Section (Cut-off titer 1:80)

'By Zhuhai S.E.Z Haitai Biological Pharmaceuticals Co., Ltd. (IgG positive)

${ }^{\mathrm{d}}$ By Shenzhen Combined Biotech Co., Ltd. (IgG positive)

${ }^{\text {B }}$ y Shanghai Touching Technology Co., Ltd. (IgG positive)

'By Hubei Academy of Medical Sciences (IgG or CAg positive)

${ }^{9}$ By Zhejiang Institute of Parasitic Disease (IgG or CAg positive)

${ }^{\text {h}}$ By Animal Medicine College, China Agricultural University (IgG positive)

'By French ID-VET company (IgG positive)

'By Parasite Laboratory of Xinjiang Agricultural University (IgG positive)

${ }^{k}$ By Quicking Biotech Co., Ltd. (antigen positive)

CIs of pooled seroprevalence of all included studies were analyzed. Forest plots were used to express the results of each study and the heterogeneity among studies. Summary of seroprevalence estimates were obtained using fixed-effects or random-effects meta-analyses which were determined by the $\mathrm{I}^{2}$ statistic (inverse variance index), which describes the percentage of variation between studies that is due to heterogeneity rather than chance. $\mathrm{I}^{2}$ does not inherently depend upon the number of studies considered, with values of 25,50 and $75 \%$ corresponding to low, moderate, and high degrees of heterogeneity, respectively [27].

Potential sources of heterogeneity were investigated further by arranging groups of studies according to potentially relevant characteristics. In this study, subgroup analysis was stratified by group (i.e. stray or pet), gender (male or female), age ( $\leq 1$ year, $>1$ year $\leq 3$ years, or $>$ 3 years), geographical regions (Eastern region including: Beijing, Tianjin, Hebei Province, Liaoning Province, Shanghai, Jiangsu Province, Zhejiang Province, Fujian
Province, Shandong Province, Guangdong Province and Hainan Province; Central region including: Shanxi Province, Jilin Province, Helongjiang Province, Anhui Province, Jiangxi Province, Henan Province, Hubei Province and Hunan Province; or Western region including: Sichuan Province, Chongqing, Guizhou Province, Yunnan Province, Tibet Autonomous Region, Shanxi Province, Gansu Province, Qinghai Province, Ningxia Hui Autonomous Region, Xinjiang Uygur Autonomous region, Guangxi Zhuang Autonomous Region and Inner Mongolia Autonomous Region), survey seasons (Spring, Summer, Autumn and Winter), and main serological tests. Meta-regression was used to investigate any significant difference between/among subgroups and the value of an odds ratio was calculated.

\section{Bias and sensitivity tests}

The across-study bias (publication bias) was examined by funnel plots. In addition, the statistical significance was assessed by the Egger's regression asymmetry test 
[28] and Begg rank correlation method [29]. The Duval \& Tweedie non-parametric 'fill and trim' linear random method was used to test and adjust for publication bias [30]. To test the robustness of a pooled estimate, we evaluated the effect of each study on the pooled seroprevalence by excluding single studies sequentially (i.e. estimated based on 37 studies each time). A study was deemed to have no influence if the pooled estimate without it (i.e. $n=37$ ) was within the $95 \%$ confidence limits of the overall seroprevalence ( $n$ = 38) [31].

Extracted data were entered into Microsoft Office Excel 2007 and Stata 12.0 was used in all statistical analyses.

\section{Results}

Search results and eligible studies

We retrieved 856 published studies through five databases and the reference lists of relevant studies (Fig. 1). A total of 775 records were excluded through an initial screening of the titles and/or abstracts. A further 28 records were excluded when taking duplication into account. The remaining 53 full-text articles were assessed, of which 15 records were further excluded according with our inclusion criterion. A total of 38 studies [32-69] were included in this meta-analysis.

\section{Characteristics of the eligible studies}

Table 1 shows the characteristics of the final 38 studies eligible for inclusion, which covered 15 provinces and municipalities. The years of the studies performed and published ranged from 1991 to 2015 and from 1995 to 2016, respectively. The total number of cats was 7,285 , with a range of 27 to 589 per study. Serological assays used in eligible studies retrieved only involved four tests including Enzyme Linked Immunosorbent Assay (ELISA, $n=22$ ), Indirect Hemagglutination Test (IHA, $n=10$ ), Modified Agglutination Test (MAT, $n=4)$, and Test Paper $(n=2)$. The evaluated scores indicating the quality of selected studies were from 6 to 10 .

\section{Pooling and heterogeneity analyses}

The seroprevalence estimates of $T$. gondii in cats are shown in a forest plot (Fig. 2). Toxoplasma gondii seroprevalence of each study varied from 3.9 to $79.4 \%$ (median 20.3\%) with substantial heterogeneity among studies $\left(\chi^{2}=1,192.78, P<0.001 ; I^{2}=96.9 \%, 95 \%\right.$ CI: 96.1-97.7). The pooled overall seroprevalence was

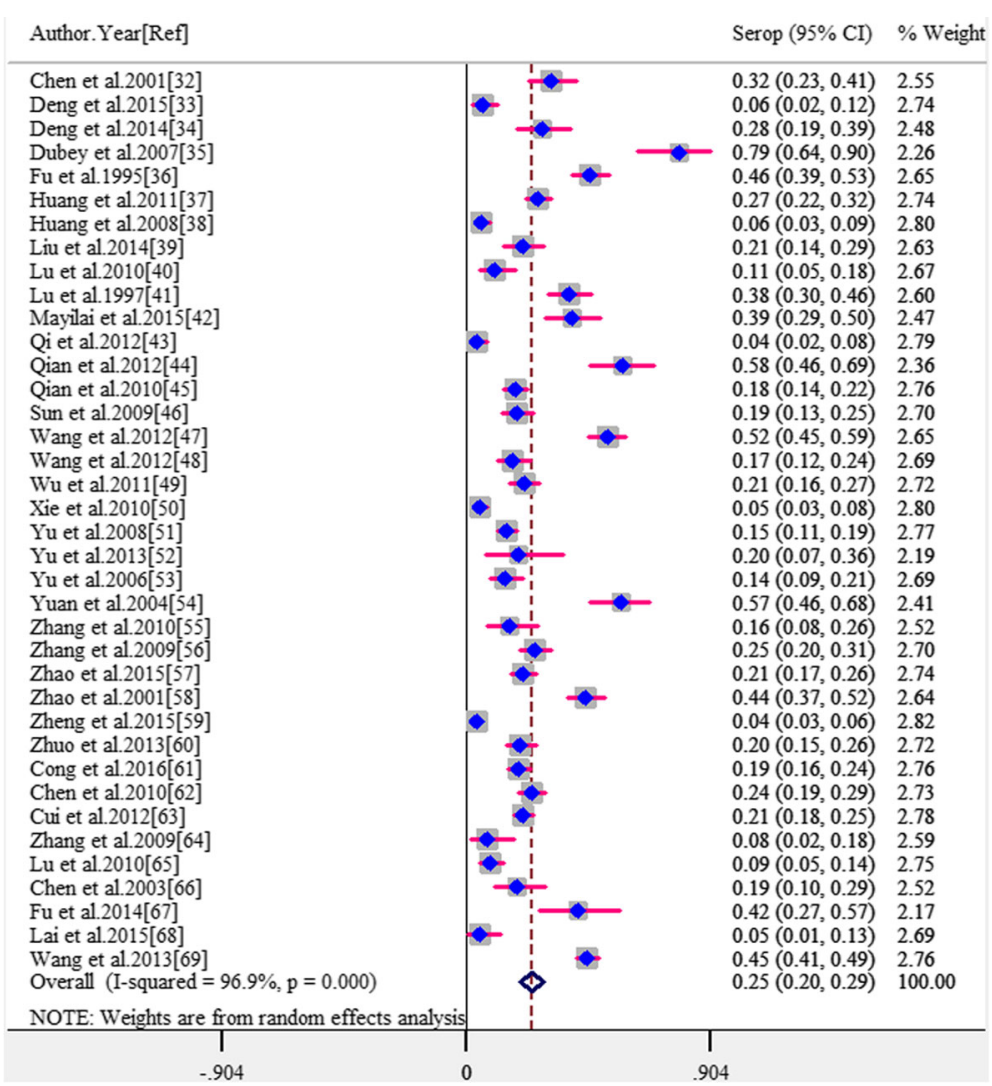

Fig. 2 Forest plot of the seroprevalence estimates of T. gondii in cats with random-effects analyses 
24.5\% (95\% CI: 20.1-29.0) when calculated using the random-effects model.

The pooled estimates by potential risk factors are presented in Table 2. In subgroup analyses, because there was a significantly high level of heterogeneity among studies within most subgroups, all estimates of the pooled seroprevalence for each subgroup were calculated using the random-effects model. Of the 38 studies, 33 provided information on the groups of cats investigated (12 about stray cats and 28 about pet cats), and the pooled seroprevalence was significantly higher in stray cats $(40.9 \%)$ than in pet cats $(16.7 \%)(P<0.001 ; \mathrm{OR}=$ 3.00; 95\% CI: 1.60-5.64) (Fig. 3). In the eight studies which presented data from both stray and pet cats, the seroprevelance was also significantly higher in stray cats $(35.9 \%)$ than in pet cats $(13.0 \%)(P<0.001$; OR $=4.87$; 95\% CI: 2.10-11.30). The seroprevalence varied from 17.4 to $31.6 \%$ among three age groups (Fig. 4) and the difference was also significant $(P<0.05)$, as seen in Table 2. A total of 13 studies provided estimates about gender, but no significant difference was observed between male and female cats $(P=0.743$; OR $=1.07$; $95 \%$ CI: $0.67-1.65)$. Similarly, no significant difference was observed among survey seasons $(P=0.911)$ as detailed in Table 2. On the basis of geographical regions, the lowest seroprevalence $(17.4 \%)$ was in Western China and the highest (32.3\%) was in Central China but with no significant difference among regions $(P=0.469)$. When stratified according to the main serological test used, no significant difference was found among the three main methods $(P=0.109)$, as see in Table 2 . Two studies applied a different method (i.e. Test paper) to screen $T$. gondii antigens in cats' serum. After excluding these two studies, the pooled seroprevalence and its 95\% CI were 24.9\% (95\% CI: 20.3-29.0), which was closely aligned with the previous estimates.

\section{Bias}

The funnel plots showed no publication bias (see Fig. 5), which was also confirmed from Egger's test (the bias coefficients $\mathrm{b}=2.49 ; 95 \% \mathrm{CI}:-7.25-9.23 ; t=1.06, P=0.294$ ). No theoretical missing study was filled by the Duval and Tweedie non-parametric method (see Additional file 2).

\section{Sensitivity tests}

The sensitivity tests indicated that all single-studyomitted estimates lay within the $95 \% \mathrm{CI}$ of the respective overall seroprevalence (see Additional file 2). This suggested that the pooled seroprevalence was not substantially influenced by any single study. The stability of such results validated the rationality and reliability of our analyses.

Table 2 Pooled estimates of T. gondii in cats by potential risk factors with meta-analysis

\begin{tabular}{|c|c|c|c|c|c|c|c|c|c|c|}
\hline \multirow{2}{*}{\multicolumn{2}{|c|}{$\begin{array}{l}\text { Factors related to T. gondii } \\
\text { seroprevalence in cats }\end{array}$}} & \multirow{2}{*}{$\begin{array}{l}\text { No. of } \\
\text { studies } \\
\text { included }\end{array}$} & \multirow{2}{*}{$\begin{array}{l}\text { No. of } \\
\text { positive } \\
\text { cats }\end{array}$} & \multirow{2}{*}{$\begin{array}{l}\text { Total } \\
\text { no. of } \\
\text { cats }\end{array}$} & \multirow{2}{*}{$\begin{array}{l}\text { Pooled } \\
\text { seroprevalence } \\
(95 \% \mathrm{Cl})\end{array}$} & \multicolumn{3}{|c|}{ Heterogeneity } & \multicolumn{2}{|c|}{ Meta-regression } \\
\hline & & & & & & $\overline{Q\left(x^{2}\right)}$ & Q-P & $\overline{I^{2}(\%)}$ & $P$-value & OR $(95 \% \mathrm{Cl})$ \\
\hline \multicolumn{2}{|l|}{ Overall } & 38 & 1,650 & 7,285 & $0.245(0.201-0.290)$ & $1,192.78$ & $<0.001$ & 96.90 & & \\
\hline \multirow[t]{2}{*}{ Group } & Stray & 12 & 400 & 1,261 & $0.409(0.154-0.664)$ & $2,020.66$ & $<0.001$ & 99.50 & 0.001 & $3.00(1.60-5.64)$ \\
\hline & Pet & 28 & 958 & 5,284 & $0.167(0.124-0.209)$ & 676.81 & $<0.001$ & 96.00 & & Reference \\
\hline \multirow[t]{2}{*}{ Gender } & Male & 14 & 261 & 1,333 & $0.212(0.170-0.255)$ & 42.46 & $<0.001$ & 71.70 & 0.743 & $1.07(0.67-1.65)$ \\
\hline & Female & 14 & 225 & 1,196 & $0.200(0.156-0.244)$ & 45.8 & $<0.001$ & 73.80 & & Reference \\
\hline \multirow[t]{3}{*}{ Age } & $Y>3$ & 12 & 318 & 1,115 & $0.316(0.229-0.403)$ & 118 & $<0.001$ & 90.70 & 0.018 & $2.77(1.39-5.53)$ \\
\hline & $1<Y \leq 3$ & 9 & 102 & 523 & $0.195(0.127-0.263)$ & 35.23 & $<0.001$ & 77.30 & & 1. $54(0.72-3.30)$ \\
\hline & $Y \leq 1$ & 12 & 335 & 1,249 & $0.174(0.076-0.272)$ & 238.78 & $<0.001$ & 95.40 & & Reference \\
\hline \multirow[t]{4}{*}{ Survey season } & Spring & 3 & 87 & 335 & $0.282(0.181-0.384)$ & 8.47 & 0.014 & 76.40 & 0.911 & $1.15(0.46-2.92)$ \\
\hline & Summer & 3 & 58 & 259 & $0.226(0.175-0.276)$ & 0.93 & 0.628 & 0 & & $0.90(0.34-2.36)$ \\
\hline & Autumn & 3 & 45 & 219 & $0.249(0.099-0.398)$ & 10.37 & 0.006 & 80.70 & & $0.91(0.34-2.43)$ \\
\hline & Winter & 3 & 43 & 176 & $0.247(0.206-0.289)$ & 1.06 & 0.589 & 0 & & Reference \\
\hline \multirow[t]{3}{*}{ Region } & Eastern & 28 & 1,308 & 5,894 & $0.249(0.197-0.302)$ & $1,010.27$ & $<0.001$ & 97.30 & 0.469 & $1.43(0.54-3.79)$ \\
\hline & Central & 4 & 165 & 433 & $0.323(0.161-0.484)$ & 41.86 & $<0.001$ & 92.80 & & $2.35(0.58-9.45)$ \\
\hline & Western & 6 & 177 & 958 & $0.174(0.105-0.243)$ & 42.41 & $<0.001$ & 88.20 & & Reference \\
\hline \multirow[t]{3}{*}{ Serological test } & ELISA & 22 & 895 & 4,556 & $0.207(0.155-0.259)$ & 619.24 & $<0.001$ & 96.60 & 0.109 & $0.29(0.10-1.08)$ \\
\hline & $\mathrm{IHA}$ & 10 & 469 & 1,548 & $0.272(0.157-0.388)$ & 323.63 & $<0.001$ & 97.20 & & $0.44(0.13-1.50)$ \\
\hline & MAT & 4 & 181 & 681 & $0.432(0.229,0.635)$ & 99.79 & $<0.001$ & 97.00 & & Reference \\
\hline
\end{tabular}

Abbreviations: 95\% CI 95\% confidence interval, ELISA Enzyme Linked Immunosorbent Assay, $\mathrm{I}^{2}$, the inconsistency index describing the percentage of variability due to heterogeneity rather than sampling error; IHA Indirect Haemagglutination test, MAT Modified Agglutination Test, Q Cochran's Q-tests for heterogeneity, Q-P p-value of Q-tests The figures in bold are for a significant difference between/among subgroups with Meta-regression at the level of 0.05 


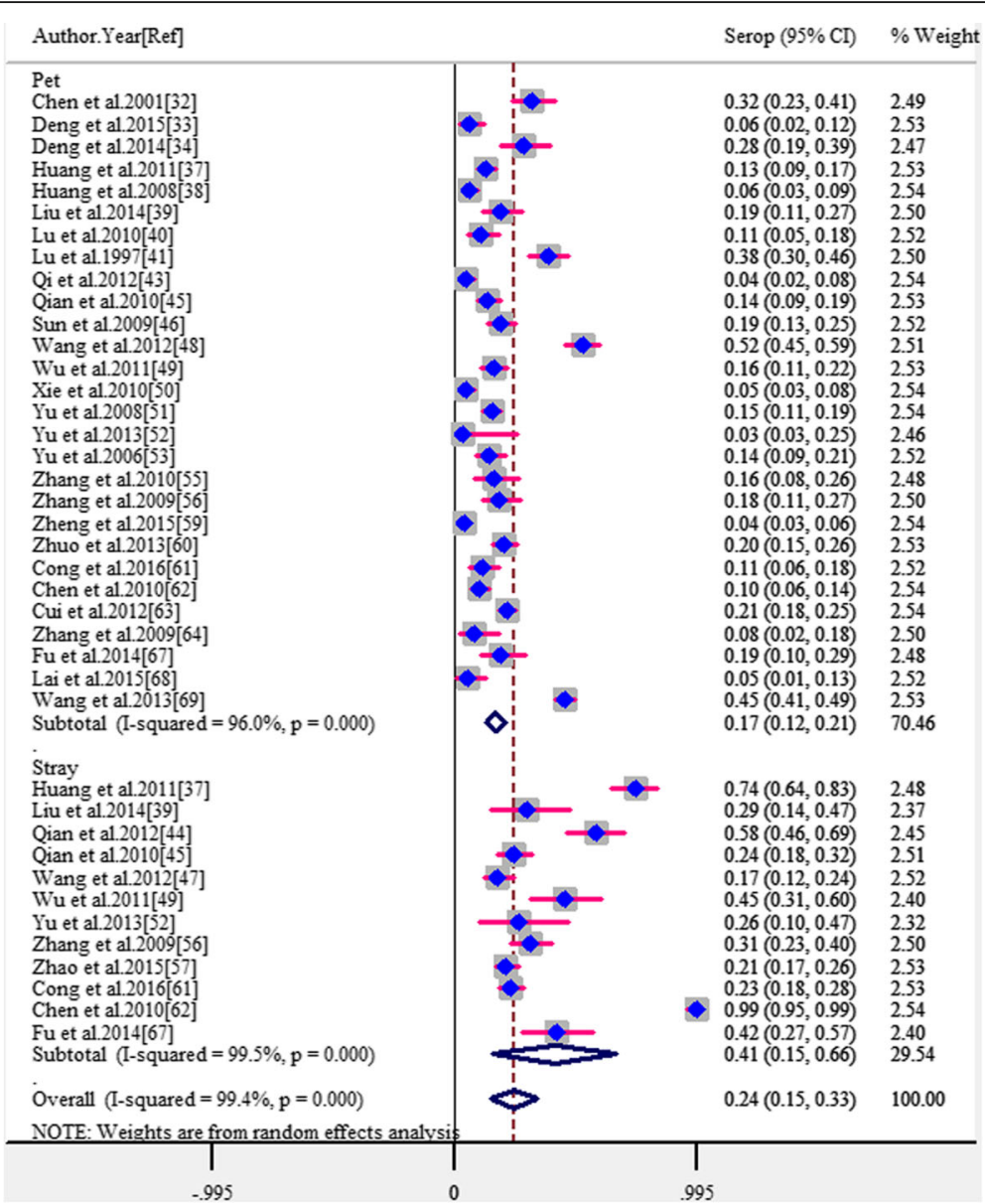

Fig. 3 Forest plot of the seroprevalence estimates of $T$. gondii in cats by stray or pet cats

\section{Discussion}

In this study, we searched five databases and identified a total of 38 relevant articles which contained eligible data on the seroprevalence of $T$. gondii in 7,285 cats across mainland China. To our knowledge, this is the first study to assess the national level of $T$. gondii seroprevalence in cats, which given the intimate relationship between cats and humans and the consequences of $T$. gondii infections in pregnant women and immunocompromised people, could be of great importance to public health and associated control measures. The overall seroprevalence of $T$. gondii in cats in mainland China from 1991 to 2015 was 24.5\% (95\% CI: 20.1-29.0). Although comparable with the prevalence recorded in Spain $(25.5 \%$ in pet cats and 36.9\% in stray cats) [70] and much lower than in Ethiopia (87.72\%) [71] and Estonia (60.8\%) [72], it was much higher than in the neighbouring country Japan (5.4\% in pet cats) $[73,74]$. Our study shows a moderate seroprevalence of $T$. gondii in cats in mainland China when compared to the average seroprevalence of $30-40 \%$ worldwide [1]. In our research two factors (stray or domestic, and cat age) were significantly associated with $T$. gondii seroprevalence.
There was high heterogeneity in seroprevalence levels in cats across mainland China among the eligible studies, but no significant publication bias was found at our cutoff level of 0.05 with either Egger's test, or DuvalTweedie's method. This high heterogeneity index is suggestive of potential variations, which could be due to real characteristics of cats surveyed, geographical regions, surveyed seasons or due to study effects such as diagnostic methods. To trace the source of heterogeneity, cats were first divided into two subgroups, stray cats or pet cats. In stray cats the pooled seroprevalence of $T$. gondii infection was significantly higher than in pet cats. This is consistent with studies reported in Spain [70], Tehran [75] and Brazil [76]. This higher seroprevalence in stray cats may be associated with their hunting and diet habits, as a stray cat lives outdoors, hunts and potentially feeds on oocyst contaminated scraps and garbage and/or Toxoplasma-infected wild birds and rodents, with more risk of ingestion of the parasite. Although the seroprevalence in pet cats is lower than in strays, nearly 1 in 5 pet cats has been exposed to $T$. gondii and the number of pet cats is rapidly increasing in China, strongly associated with the rapid 


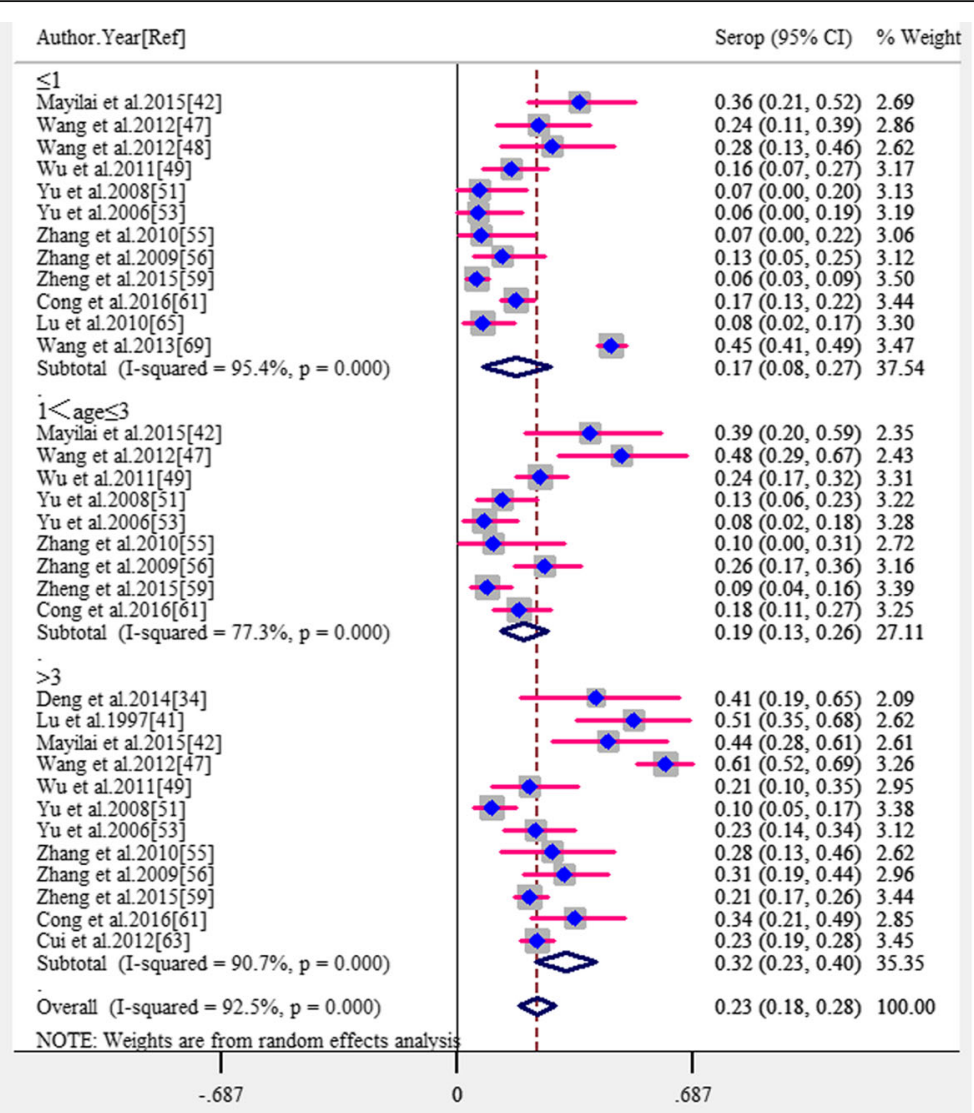

Fig. 4 Forest plot of the seroprevalence estimates of $T$. gondii in cats by age groups ( $\leq 1$ year-old, $\leq 3$ year-old or $>3$ year-old) with random-effects analyses

social change of the country [21]. Some practices such as feeding pet cats raw meat may increase the chance of exposure to T. gondii and transmission from them [20].

The seroprevalence in cats increased with cat age, ranging from $17.4 \%$ in cats $\leq 1$ years of age in comparison

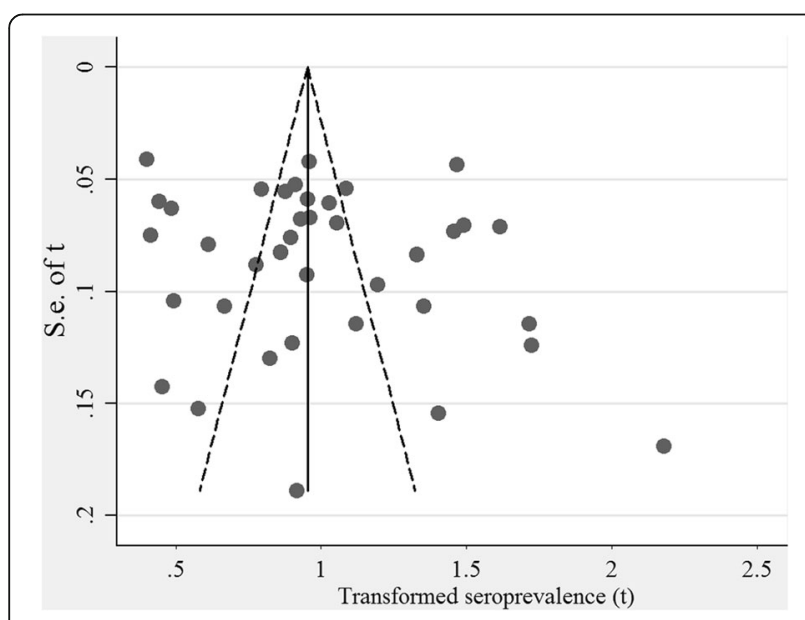

Fig. 5 Funnel plots of the arcsine transformed seroprevalence estimates (t) of T. gondii in cats Abbreviation: se, standard error with $31.6 \%$ in cats $>3$ years of age. This agrees with a study in which a significantly higher seroprevalence of T. gondii is observed in an adult cat group compared with the juveniles $[77,78]$. This is likely to be explained by the positive association between an increase in age, with an increased risk of exposure to $T$. gondii oocysts over time, and a long lived immune response to this. No significant difference was observed between sexes, again supporting a study which showed that sex was not considered a determining factor for infection with $T$. gondii in cats [49]. This indicates that there is little or no difference between the cat sexes in both infection risk behaviour and/or immunological susceptibility.

Toxoplasma gondii is widely distributed, especially in warm, moist and low altitude regions [79], and at temperate to tropical temperatures oocysts remain infectious for up to 1.5 years [80]. Thus, it would be predicted that infections in cats may differ among regions or seasons in relation to climate [81]. Indeed, after the data were stratified based on geographical regions, cats in Central China including Hunan, Hubei and Henan provinces, characterized by a subtropical monsoon climate and suitable for the survival and sporulation of oocysts in 
the wild, had a higher seroprevalence than in other regions although this was not significant in the overall analyses. This is partly due to a low number of studies from the central region. In terms of seasons in which surveys were conducted, the highest pooled seroprevalence in cats was in Spring and the lowest in Summer, but this was also not significant, again likely due to small sample sizes within the studies (i.e. 176 to 335 cats per subgroup).

Although the serological methods to identify T. gondii infection differed among studies, ELISA, IHA and MAT were the most common and there were no significant differences among these methods in the reported seroprevalences. In testing seroprevalence of $T$. gondii in cats with ELISA, IHA and LAT (Latex Agglutination Test), the results from these three kits were similar [74]. By using MAT and ELISA in detecting $T$. gondii in cats, no significant difference was seen between the two methods [82]. All three diagnostic methods were also compared for the routine screening of $T$. gondii infections and were shown to have good compliance with each other [83]. All of these findings, including our meta-regression analysis here and meta-analyses on the adjusted seroprevalence with both sensitivity and specificity of each test (see Additional file 3; and original data, see Additional file 4), suggest that testing method was unlikely to be a significant source of heterogeneity in this analysis.

There are two main limitations in our meta-analysis. First, as the numbers of eligible studies in subgroups are small, the estimates and the predictive values of the risk factors should be assessed accordingly. Secondly, no information about cats' environment, such as rural or urban areas, has been described, thus making it impossible to assess the effect of this potentially important factor with regard to implementing control. However, this is the first study, to our knowledge, to estimate the overall seroprevalence of $T$. gondii in cats in mainland China, leading the way for future research in areas and cat groups which might be informative for future control interventions if required. In addition, there was no information on potentially important issues such as: (i) are pet cats allowed to go outside? and (ii) the effect of rural versus urban areas on $T$. gondii seroprevalence levels. Future studies incorporating the potential differences between urban and rural areas are required if we are to reduce overall infection levels in China.

\section{Conclusions}

The seroprevalence of $T$. gondii in cats in mainland China was moderate (up to 24\%) and associated with cats' activities (i.e. stray or pet cats) and cat age. However, due to the increasing ownership of pet cats in China and the intimate association between cats and humans, particularly with China's large susceptible population, and nearly 1 on 5 pet cats being $T$. gondii seropositive this might present a significant exposure risk to cat owners. Therefore, in order to reduce the infections of $T$. gondii in humans via cat contacts (or/and eating raw meat) and the environmental contamination with $T$. gondii oocysts by stray or pet cats, approaches such as educational programs on the potential risk of $T$. gondii when raising cats, improvement in personal hygiene, and good pet-keeping management should be recommended.

\section{Additional files}

Additional file 1: Checklist of items to include when reporting a metaanalysis. (DOC $73 \mathrm{~kb}$ )

Additional file 2: Filled funnel plot by the Duval \& Tweedie method and sensitivity analyses. (DOC $73 \mathrm{~kb}$ )

Additional file 3: Meta-analyses on the seroprevalence of T. gondii in cats adjusted with sensitivity and specificity of each test. (DOC $188 \mathrm{~kb}$ )

Additional file 4: The data generated from each included article during this study. (DOC $242 \mathrm{~kb}$ )

\section{Abbreviations}

$\mathrm{Cl}$ : Confidence intervals; CBM: Chinese biomedical literature database; CNKI: China national knowledge infrastructure; ELISA: Enzyme linked immunosorbent assay; IHA/IHAT: Indirect haemagglutination test; MAT: Modified agglutination test; OR: Odds ratio; PRISMA: Preferred reporting items for systematic reviews and meta-analyses

\section{Acknowledgements}

Not applicable.

\section{Funding}

$\mathrm{DL}$ is funded by the National Science Foundation of China (No. 81273141). PHLL is funded by an ERC starting grant (SCHISTO_PERSIST, 68808) and the Wellcome Trust ISSF (105614/Z/14/Z) and a Lord Kelvin Adam Smith Leadership Fellowship.

Availability of data and materials

All data generated or analysed during this study are included in this published article and its Additional files.

Authors' contributions

$\mathrm{HD}$ and $\mathrm{DL}$ conceived of and designed the study. HD and YG carried out the screen of the literature and data extraction, and checked by YD. HD analyzed the results with help of DL and PHLL. HD drafted the manuscript, and DL, YG and PHLL revised the manuscript. All authors read and approved the final manuscript.

\section{Competing interests}

The authors declare that they have no competing interests.

\section{Consent for publication}

Not applicable.

Ethics approval and consent to participate

This research was based on information/data extracted from published studies and no ethical approval was acquired.

\section{Author details}

${ }^{1}$ Department of Epidemiology and Statistics, School of Public Health, Soochow University, Suzhou 215123, China. ${ }^{2}$ Jiangsu Key Laboratory of Preventive and Translational Medicine for Geriatric Diseases, School of Public Health, Soochow University, Suzhou 215123, People's Republic of China. ${ }^{3}$ Institute of Biodiversity, Animal Health and Comparative Medicine and Wellcome Trust Centre for Molecular Parasitology, University of Glasgow, 
Glasgow GL12 8QQ, UK. “Department of Infectious Disease Epidemiology, Imperial College London, London W2 1PG, UK.

\section{Received: 4 August 2016 Accepted: 4 January 2017 Published online: 13 January 2017}

\section{References}

1. Dubey JP. Toxoplasmosis of animals and humans. Boca Raton, NW: CRC Press; 2010.

2. Hill DE, Dubey JP. Toxoplasma gondii prevalence in farm animals in the United States. Int J Parasitol. 2013;43:107-13.

3. Lamberton P, Donnelly C, Webster JP. Specificity of the Toxoplasma gondiialtered behaviour to definitive versus non-definitive host predation risk. Parasitology. 2008;135:1143-50.

4. Ma MJ, Tan G, Jiang X, OuYang Y. The epidemiology and prevention and control of toxoplasmosis in dogs and cats. Hubei Anim Husb Vet. 2012:25-6.

5. Dubey J. Oocyst shedding by cats fed isolated bradyzoites and comparison of infectivity of bradyzoites of the VEG strain Toxoplasma gondii to cats and mice. J Parasitol. 2001;87:215-9.

6. Dubey JP, Tiao N, Gebreyes WA, Jones JL. A review of toxoplasmosis in humans and animals in Ethiopia. Epidemiol Infect. 2012;140:1935-8,

7. Webster J. Rats, cats, people and parasites: the impact of latent toxoplasmosis on behaviour. Microbes Infect. 2001;3:1037-45.

8. Gu XY, Zhao XX. Research progress of infection with Toxoplasma gondii during pregnancy. Chin J Obstet Gynecol Pediatr. 2015;11:660-2.

9. Luft BJ, Remington JS. AIDS commentary. Toxoplasmic encephalitis J Infect Dis. 1988;157:1-6.

10. Yolken RH, Bachmann S, Rouslanova I, Lillehoj E, Ford G, Torrey EF, Schroeder J. Antibodies to Toxoplasma gondii in individuals with firstepisode schizophrenia. Clin Inf Dis. 2001;32:842-4.

11. Li XR. New epidemiological characteristics of Toxoplasma gondii infections. Prog Vet Med. 2010;31:234-6.

12. Palmer BS. Meta-analysis of three case controlled studies and an ecological study into the link between cryptogenic epilepsy and chronic toxoplasmosis infection. Seizure. 2007;16:657-63.

13. Ling VJ, Lester D, Mortensen PB, Langenberg PW, Postolache TT. Toxoplasma gondii seropositivity and suicide rates in women. J Nerv Ment Dis. 2011;199:440-4.

14. Havelaar AH, Kirk MD, Torgerson PR, Gibb HJ, Tine H, Lake RJ, et al. World health organization global estimates and regional comparisons of the burden of foodborne disease in 2010. Plos Medicine. 2015;12:1-23.

15. Wu ZY. The new situation and challenges of prevention and control of AIDS in China. Chin J Public Health. 2011;27:1505-7.

16. NBS. China statistical yearbook, 2014. Beijing: China Statistics Press; 2014.

17. Sun XF, Lou YG, Liu PZ. Study on Toxoplasma infection among some petbreeders at urban area in Qingdao in 2006. Prev Med Tribune. 2007;13:133-4.

18. Xu LQ, Chen YD, Sun FH, Cai L, Fang YY, Wang LP, et al. A national survey on current status of the important parasitic diseases in human population. Chin J Parasitol Parasit Dis. 2005;23:332-40.

19. Zhang JZ, Chen HZ, Xu JF. The status of Toxoplasma gondii infection in our country. Prog Vet Med. 2008;29:101-4.

20. Liu Q, Jin HT. Toxoplasma gondii infection and its control in pets. Chin J Comp Med. 2010;20:105-8.

21. Chen N, Wu Y, HUang XK, Ye FW. Discussion on the relationship between pet information management and pet economic development in China. Times Finance. 2016;164:8.

22. Sutterland AL, Fond G, Kuin A, Koeter MWJ, Lutter R, Gool TV, et al. Beyond the association. Toxoplasma gondii in schizophrenia, bipolar disorder, and addiction: systematic review and meta-analysis. Acta Psychiatr Scand. 2015;132:161-79.

23. Jaroslav F. Schizophrenia and Toxoplasma gondii: an undervalued association? Expert Rev Anticancer Ther. 2015;13:817-20.

24. Moher D, Liberati A, Tetzlaff J, Altman DG, Group TP. Preferred reporting items for systematic reviews and meta-analyses: the PRISMA statement. Int J Surg. 2010;8:336-41.

25. Srivastava M, Abbas M. Topics in biostatistics. Totowa: Humana Press; 2007

26. Barendregt JJ, Doi SA, Yong YL, Norman RE, Vos T. Meta-analysis of prevalence. J Epidemiol Comm Health. 2013;67:974-8.

27. Higgins JP, Thompson SG. Quantifying heterogeneity in a meta-analysis. Stat Med. 2002;21:1539-58.
28. Minder C, Egger M, Smith GD, Schneider M. Bias in meta-analysis detected by a simple, graphical test. BMJ. 1997;315:629-34.

29. Begg CB, Mazumdar M. Operating characteristics of a rank correlation test for publication bias. Biometrics. 1995;50:1088-101.

30. Sue D, Richard T. Trim and fill: a simple funnel-plot-based method of testing and adjusting for publication bias in meta-analysis. Biometrics. 2000; 56:455-63.

31. Gao L, Zhang L, Jin Q. Meta-analysis: prevalence of HIV infection and syphilis among MSM in China. Sex Transm Infect. 2009;85:354-8.

32. Chen CY. Study on Toxoplasma gondii infection of pets and population. Chin J Zoonoses. 2001;17:76-7.

33. Deng B, Ge J, Yang XC, Li KH, Zhou JP. Seroprevalence of Toxoplasma gondi infection in domestic dogs and cats in urban area of Shanghai in. Shanghai J Anim Husb and Vet Med. 2014;2015:44-5.

34. Deng GQ, Ou LY, Tang XM, Wang WG. Seroprevalence of Toxoplasma gondii infection in cats and dogs in urban area of Changsha. Chin J Vet. 2014;50:74-5.

35. Dubey JP, Zhu XQ, Sundar N, Zhang H, Kwok OC, Su C. Genetic and biologic characterization of Toxoplasma gondii isolates of cats from China. Vet Parasitol. 2007;145:352-6.

36. Fu B, Zhao YQ, Yang BJ, Han GD, Shao QF, Li JM, et al. Epidemiological investigations on toxoplasmosis in Shandong province. Chin J Parasit Dis Cont. 1995;08:205-7.

37. Huang LQ, Li H, He SG, Mao HR. Epidemiology survey of Toxoplasma gondii infection in dogs, cats and pigs in Zhejiang areas. Chin J Vet Med. 2011;47:39-41.

38. Huang SM, Zhou QP, Cui K, Huang ZS, Li QX. Analysis of Toxoplasma gondii infection in pet dogs and cats in Haikou city. Chin Trop Med. 2008;8: $1462,392$.

39. Liu QX, Wang S, Wang LQ, Xing J, Gao WJ, Liu GF, et al. Seroprevalence of Toxoplasma gondii infection in dogs and cats in Zhenjiang city, eastern China. Asian Pac J Trop Biomed. 2014;4:725-8.

40. Lu AT, Gao Y, Du S. Survey on cats and dogs infected with Toxoplasma gondii at part area of Inner Mongolia. Anim Husb Feed Sci. 2010;31:155-6.

41. Lu Q, Huang AM. Seroprevalence of Toxoplasma gondii infection in outpatient cats in Shanghai. Chin J Zoonoses. 1997;13:69-70.

42. Mayilai, Chen QL, Liu ML, Tuersun, Bayinzhahan. Investigation of Toxoplasma gondii infection in dogs, cats in Kuche areas. Xinjiang J Anim Husb. 2015:25-7.

43. Qi HX, Zhang HY, Zhang WJ, Zhang XM, Cao YZ. Epidemiology survey of toxoplasmosis in pets (dogs, cats). Beijing Agricult J. 2012:70-1.

44. Qian W, Hui W, Su C, Dan S, Xia C, Na Y, et al. Isolation and characterization of Toxoplasma gondii strains from stray cats revealed a single genotype in Beijing. China Vet Parasitol. 2012;187:408-13.

45. Qian WF, Yu SS, Wang H, Shan D, Liu Q. Epidemiology survey of toxoplasmosis and isolation and characterization of Toxoplasma gondii strains from dogs and cats. Chengdu: Proceedings of the 2011 Annual Conference of Chinese Institute of Animal Husbandry and Veterinary; 2011. p. 718.

46. Sun $X$, Li RH, Sun HY, Zhao DM. Epidemiology survey of Toxoplasma gondii infection in pet dogs and pet cats in Beijing and surrounding regions. Heilongjiang Anim Sci Vet Med. 2009:110.

47. Wang HY, Pei SL, Hao ZF, Zhou M. Epidemiology survey of toxoplasmosis in pets in Zhengzhou. Henan J Agricult Sci. 2012;41:153-4.

48. Wang Q, Jiang W, Chen YJ, Liu CY, Shi JL, Li XT. Prevalence of Toxoplasme gondii antibodies, circulating antigens and DNA in stray cats in Shanghai. China Parasit Vectors. 2012;5:190.

49. Wu SM, Zhu XQ, Zhou DH, Fu BQ, Chen J, Yang JF, et al. Seroprevalence of Toxoplasma gondii infection in household and stray cats in Lanzhou, northwest China. Parasit Vectors. 2011:4:214-7.

50. Xie GP, Geng YJ, Zhang RL, Huang DN, Gao ST, Zhang Q, et al. Epidemiology survey of Toxoplasma gondii infection and related factors in pet dogs and domestic cats in Shenzhen. Chin Trop Med. 2010;10:1075-7.

51. Yu JH, Ding J, Xia ZF, Lin DG, Li YL, Jia JY, Liu Q. Seroepidemiology of Toxoplasma gondii infection in pet dogs and cats in Beijing. China Acta Parasitol. 2008:53:317-9.

52. Yu XQ, Wen DL, Gong DD, Zhang ZH, Gong JW, Sun FH, et al. Seroprevalence survey and analysis of toxoplasmosis in dogs and cats in Pudong New Area. Shanghai J Anim Husb Vet Med. 2013:36-7.

53. Yu YL, Fu L, Wang M. Seroprevalence of Toxoplasma gondii infection in dogs and cats in Beijing areas. Chin J Vet Med. 2006;42:7-9.

54. Yuan WY, Ma K, Yang HL. A survey of Toxoplasma gondii infection in animals in Hebei province. Chin J Schist Cont. 2004;16:72,6. 
55. Zhang H, Li P, Chai J. Epidemiology survey of toxoplasmosis in dogs and cats in Zhengzhou urban district. Heilongjiang Anim Sci Vet Med. 2010:74-5.

56. Zhang Y, Liu F, Xu X, He L, Li A, Zhang X. Serological investigation of toxoplasmosis in Beijiang district, Xinjiang province. Herb Magazine. 2009:22-4.

57. Zhao J, Cang YJ, Wang X. Investigation of Toxoplasma gondii infection in stray cats and wild animals in Beijing zoo. J Wildlife. 2015;36:270-4.

58. Zhao YQ, Zhen TM, Wang JX, Fu B, Han GD. A survey of Toxoplasma gondii infection in animals in Shandong province. J Prev Med Inf. 2001;17:185.

59. Zheng SY, Zheng F, Li SP, Duan XM, Geng JF, Jia HH. Epidemiology survey of toxoplasmosis in dogs and cats in parts of Shandong province. Chin J Vet Med. 2015:51:74-5.

60. Zhuo GR, Di HS, Lu W, Liu JD, Zhang H, Wang CF. Analysis of serum antibody of Toxoplasma gondii in cats in Taizhou area with different detection methods. Jiangsu Agricult Sci. 2013;41:190-1.

61. Cong W, Meng QF, Blaga R, Villena I, Zhu XQ, Qian AD. Toxoplasma gondii, Dirofilaria immitis, feline immunodeficiency virus (FIV), and feline leukemia virus (FeLV) infections in stray and pet cats (Felis catus) in northwest China: coinfections and risk factors. Parasitol Res. 2016;115:217-23.

62. Chen J. Epidemiology survey of Toxoplasma gondii in pet cats and dogs in Shanghai. Shanghai: Shanghai Jiaotong University; 2010.

63. Cui LL, Yu YL, Liu S, Wang BB, Zhang ZX, Wang M. The epidemiology survey of toxoplasmosa gondii in cats and dogs in Beijing. Chin J Vet. 2012;48:7-10.

64. Zhang H, Zhou DH, Zhou P, Lun ZR, Chen XG, Lin RQ, et al. Seroprevalence of Toxoplasma gondii infection in stray and household cats in Guangzhou. China Zoonoses Public Health. 2009;56:502-5.

65. Lu WY, Ha L, Cao LP, Yang LM, Xue YP. The current prevalence of toxoplasmosis in dogs and cats in Lanzhou and other five cities (states). Anim Husb Vet Med. 2010:42:109.

66. Chen HR, Huang BJ. The report of Toxoplasma serological survey. Haebing, Heilongjiang: Small animal medicine; 2003. p. 181-2.

67. Fu LL, Yan C, Liu ZZ, Kong DL, Lv L, Shi N. Isolation and identification of Toxoplasma gondii strains from cats in Xuzhou region. Chin J Schist Cont. 2014;26:656-7.

68. Lai PG, Li MW, Zhai XJ, Tian HY. The epidemiological survey of some zoonosis in pet cats and dogs in Beijing city. Chin J Vet Med. 2015;51:69-70.

69. Wang K. The survey of infection of Toxoplasma gondii in some animals and genetying of swine in Fujian. Fujian: Fujian Agriculture and Forestry University; 2013.

70. Miró G, Montoya A, Jiménez S, Frisuelos C, Mateo M, Fuentes I. Prevalence of antibodies to Toxoplasma gondii and intestinal parasites in stray, farm and household cats in Spain. Vet Parasitol. 2004;126:249-55.

71. Gebremedhin EZ, Tadesse G. A meta-analysis of the prevalence of Toxoplasma gondii in animals and humans in Ethiopia. Parasit Vectors. 2015;8:1-9.

72. Must K, Lassen B, Jokelainen P. Seroprevalence of and risk factors for Toxoplasma gondii infection in cats in Estonia. Vector Borne Zoonotic Dis. 2015; 15:597-601.

73. Maruyama S, Kabeya H, Nakao R, Tanaka S, Sakai T, Xuan X, et al. Seroprevalence of Bartonella henselae, Toxoplasma gondii, FIV and FeLV Infections in domestic cats in Japan. Microbiol Immunol. 2003:47:147-53.

74. Lappin MR, Powell CC. Comparison of latex agglutination, indirect hemagglutination, and ELISA techniques for the detection of Toxoplasma gondii-specific antibodies in the serum of cats. J Vet Int Med. 1991;5:299-301.

75. Haddadzadeh HR, Khazraiinia P, Aslani M, Rezaeian M, Jamshidi S, Taheri M, et al. Seroprevalence of Toxoplasma gondii infection in stray and household cats in Tehran. Vet Parasitol. 2006;138:211-6.

76. Coelho WM, do Amarante AF, Apolinário Jde C, Coelho NM, de Lima VM, Perri SH, Bresciani KD. Seroepidemiology of Toxoplasma gondii, Neospora caninum, and Leishmania spp. infections and risk factors for cats from Brazil. Parasitol Res. 2011;109:1009-13.

77. Gauss CB, Almería S, Ortuño A, Garcia F, Dubey JP. Seroprevalence of Toxoplasma gondii antibodies in domestic cats from Barcelona. Spain J Parasitol. 2003;89:1067-8.

78. Masatani T, Takashima Y, Takasu M, Matsuu A, Amaya T. Prevalence of antiToxoplasma gondii antibody in domestic horses in Japan. Parasitol Int. 2015; 65.

79. Wang YB, Yang XD, Yang GR. Progress in research of toxoplasmosis. Chin Trop Med. 2012;12:146-150.

80. Xiao XP, Xu HZ, Yu B, Yang MS, Ren RQ, Shi KZ. The epidemiological trend and prevention and control measures of zoonotic toxoplasmosis in Guizhou. Chin Anim Seed. 2013:25-8.

81. Schares G, Ziller M, Herrmann DC, Globokar MV, Pantchev N, Conraths FJ. Seasonality in the proportions of domestic cats shedding Toxoplasma gondii or Hammondia hammondi oocysts is associated with climatic factors. Int J Parasitol. 2016;46:263-73.
82. Cui LL, Yu YL, Liu S, Wang BB, Wang M. Comparing analysis of modified agglutination test (MAT) and enzyme-linked immunosorbent assay (ELISA) in detection of the antibody against Toxoplasma gondii. Wuhan, Hubei: China Institute of animal science and veterinary medicine branch congress and academic seminar; 2011. p. 82-3.

83. Zhang SY, Wei MX, Wang LY, Ding ZY, Xu XP. Comparative analysis of modified agglutination test (MAT) and indirect coagulation test (IHAT) and enzyme linked immunosorbent assay (ELISA) for detection of Toxoplasma gondii antibody. J Parasit Medcal Insects. 2001;8:199-203.

\section{Submit your next manuscript to BioMed Central and we will help you at every step:}

- We accept pre-submission inquiries

- Our selector tool helps you to find the most relevant journal

- We provide round the clock customer support

- Convenient online submission

- Thorough peer review

- Inclusion in PubMed and all major indexing services

- Maximum visibility for your research

Submit your manuscript at www.biomedcentral.com/submit
) Biomed Central 